\section{Irrigation Method and Temperature of Water Affect Height of Potted Easter Lilies}

\author{
Theo Blom ${ }^{1}$ and David Kerec \\ University of Guelph, Department of Plant Agriculture, 4890 Victoria Avenue \\ N., Vineland Station, ON, Canada, LOR 2EO
}

\author{
Wayne Brown \\ Ontario Ministry of Agriculture and Food, 4890 Victoria Avenue N., Vineland \\ Station, ON, Canada, LOR 2EO \\ Dave Kristie \\ Department of Biology, Acadia University, Wolfville, Nova Scotia
}

Additional index words. cold shock, Lilium longiflorum, temperature shock

\begin{abstract}
Potted greenhouse-forced 'Nellie White'Easter lilies (Lilium longiflorum Thunb.) were irrigated from emergence with water at $2,5,8,11$, or $15^{\circ} \mathrm{C}$ either onto the shoot apex (overhead) or onto the substrate for a $0,2-, 4-, 6-, 8-, 10-$, or 12-week period. Control treatment was at $18{ }^{\circ} \mathrm{C}$, either overhead or on substrate. When irrigation water was applied overhead for the entire period between emergence and flowering (12 weeks), plant height increased linearly with the temperature of irrigation water $\left(1.75 \mathrm{~cm} /{ }^{\circ} \mathrm{C}\right)$. As the period of application with cold water increased from 0 to 12 weeks, plant height decreased both in a linear and a quadratic manner. Forcing time was negatively correlated with height with the shortest plants delayed by 3 to 6 days. Water temperature did not affect bud abortion or the number of yellow leaves. Irrigation water temperature had no effect on plant parameters when applied directly on the substrate.
\end{abstract}

Plant height of greenhouse-forced Easter lilies (Lilium longiflorum Thunb.) needs to be controlled by commercial growers as it can increase both the aesthetics of the plant and make shipping easier. Producers are becoming increasingly apprehensive about using chemical growth regulators to control height because of increased yellowing of the lower leaves (Jiao et al., 1986), which must be removed before shipping.

Several nonchemical techniques to control plant height have been reported: 1) temperature differential (DIF) between day and night (Erwin and Heins, 1990 and 1995; Erwin et al., 1987) or temperature drop during the early morning hours; 2) mechanical (Mitchell, 1996), water or salts stress; 3) light intensity (Heins et al., 1982) or light quality (Blom et al., 1995; Mortensen and Stromme, 1987; Rajapakse et al., 1999); and 4) control of photoperiod (Smith and Langhans, 1962; Wilkins et al., 1968). All of the above techniques can be used as part of management practices for graphical tracking of Easter lily development (Fisher et al., 1997).

The effect of irrigation water temperature in regulating plant height is not well understood and few published reports are available. Chen et al. (1999) reported that cold water reduces stem elongation of tomato (Lycopersiconescu-

Received for publication 22 Oct. 2002. Accepted for publication 3 Mar. 2003. Thanks to Ednie Flower Bulbs, Inc., N.J.; Hastings, Inc., Ore.; and Crockett United Lily Growers, Calif.

${ }^{1}$ To whom requests for reprints should be addressed. E-mail:tblom@uoguelph.ca. lentum Mill.) and cabbage (Brassica oleracea L.) seedlings. Larson et al. (1990) reported on the use of cold water on Easter lily but provided few details. Because of the scarcity of information and lack of understanding of the effect of cold water on plant height control, the objectives of this study were to determine how water temperature, method of application, and time of application affect plant height, number of flower buds, and forcing time of 'Nellie White' Easter lilies.

\section{Materials and Methods}

Expt. 1. The effect of water temperature, method of application and time of day (2001). Bulbs of Easter lily 'Nellie White' (20-23 cm circumference) were received from United Bulb Co., Smith River, Calif., on 27 Oct., 2000. The bulbs, which averaged $115.4 \mathrm{~g}$ with a meristem of $2 \mathrm{~mm}$ long, were upon arrival case-cooled for 6 weeks at $6{ }^{\circ} \mathrm{C}$ (until 8 Dec.). Bulbs were then dipped in a fungicide solution (dicofol at $0.525 \mathrm{~g} \cdot \mathrm{L}^{-1}$ ) for $30 \mathrm{~min}$ and planted singly into 15 -cm-diameter (1.6-L) standard plastic pots filled with Sunshine \#4 Aggregate Plus substrate (SunGro Horticulture, Westerville, Ohio).

Plants were grown at a spacing of 20 plants/ $\mathrm{m}^{2}$ in a double acrylic greenhouse maintained at $18^{\circ} \mathrm{C}$ day $/ 18^{\circ} \mathrm{C}$ night and a 10 -h photoperiod using black-out curtains daily from 6 PM until 8 AM. Individual plants were irrigated with a nutrient solution containing $375 \mathrm{mg} \cdot \mathrm{L}^{-1}$ of $\mathrm{N}$ using $15 \mathrm{~N}-0 \mathrm{P}-12.5 \mathrm{~K}$ (Plant Products, Bramalea, Ont., Canada) at temperatures of 5,15 , or $25^{\circ} \mathrm{C}$. The solution temperatures were achieved by placing them either in a $5{ }^{\circ} \mathrm{C}$ cooler, in a $25^{\circ} \mathrm{C}$ room, or by mixing both just prior to application to obtain a $15^{\circ} \mathrm{C}$ solution. Each solution was poured manually twice weekly onto the shoot apex (overhead) of each plant or over the surface of the growing medium using a $100-\mathrm{mL}$ measuring cup. The applications started at emergence (beginning of Jan. 2001) and ended at flowering (middle of Apr. 2001). During April (last 4 months of forcing), the volume of water was increased to $150 \mathrm{~mL}$ to accommodate both the increased transpiration due to the increasing plant size and radiation. Additionally, applications were either made in early morning between 0800 and $0900 \mathrm{HR}$ (AM) or early afternoon between 1300 and $1400 \mathrm{HR}(\mathrm{PM})$. The experimental design was a complete randomized factorial with three temperatures $\left(5,10\right.$, and $\left.15^{\circ} \mathrm{C}\right)$, two timings (AM and PM), two types of application (overhead and substrate). There were 10 plants per plot and the experiment was replicated in the same greenhouse (total of 240 plants).

Expt. 2. The effect of water temperature, method of application and period of application (2002). Bulbs of Easter lily 'Nellie White' (20-23 cm circumference) were received from the United Bulb Co. on 23 Oct. 2001. Upon arrival, the bulbs weighed an average of $124.7 \mathrm{~g}$ and were immediately case-cooled for 6 weeks at $6{ }^{\circ} \mathrm{C}$. After case-cooling (meristem $19 \mathrm{~mm}$ long), the bulbs were treated and planted as described in Expt. 1. At shoot emergence (1 Jan.), individual plants were irrigated twice weekly by pouring a nutrient solution (same as in Expt.1) at 2, 5, 8, 11, 15, or $18^{\circ} \mathrm{C}$ either onto the shoot apex (overhead) or directly onto the growing medium from a $100-$ or $150-\mathrm{mL}$ measuring cup. All plants were irrigated with the same volume and on the same day. The treatments started the first week of Jan. 2002 and lasted for $2,4,6,810$, or 12 weeks. The latter treatment coincided with flowering. When a treatment period with a given temperature ended, plants were irrigated for the remainder of the trial with $18^{\circ} \mathrm{C}$ water but the method of application remained the same (overhead or substrate). Control plants were watered either overhead or on the substrate with $18{ }^{\circ} \mathrm{C}$ for all 12 weeks. Plants were grown in a glass greenhouse at $18^{\circ} \mathrm{C}$ day $/ 18^{\circ} \mathrm{C}$ night at a spacing of 20 plants $/ \mathrm{m}^{2}$. Automatic blackout was used between sunset and sunrise to prevent light drift and eliminate twilight effect. During the experiment, a thermocouple (type $\mathrm{T}$ ) was inserted into the apex of some plants before pouring the irrigation solution overhead. Shoot apex temperatures were recorded (using a data logger) every minute for $1 \mathrm{~h}$ (LI 1000; LI-COR, Lincoln, Nebr.) following irrigation.

Plant height was measured weekly on 3 plants within a plot beginning the first week of 2002. These measurements were aimed to determine how long the growth rate belonging to a treatment temperature $\left(2,5,8\right.$, or $\left.11^{\circ} \mathrm{C}\right)$ continued to be the same, after the temperature treatment was terminated and continued with $18^{\circ} \mathrm{C}$ water. To do this, plant height of plants treated for a period of $2\left(\mathrm{P}_{2}\right), 4\left(\mathrm{P}_{4}\right), 6\left(\mathrm{P}_{6}\right)$, and 8 weeks $\left(\mathrm{P}_{8}\right)$, respectively), at a given 
temperature were compared to the height of those plants (= height difference), that were given the same temperature on a continuous sion was performed on the difference in plant height to determine the junction point using the ProcNLIN procedure (Bowley, personal communication) using SAS (Windows vers. 8.0). The junction point (j) was estimated using a joint linear regression model. This point provides an estimate of how long the response to a cold water treatment remained in effect after the treatment was terminated (and replaced with irrigation water at $18^{\circ} \mathrm{C}$ ).

This experiment was a completely randomized factorial design consisting of six nutrient solution temperatures $(2,5,8,11,15$, and $18^{\circ} \mathrm{C}$ ); two types of application (overhead and substrate); seven periods $(0,2,4,6,8$, 10 , and 12 weeks); two replications; and six plants per plot.

Expt. 3. Role of bulb size in response to water temperature (2002). Two bulb sizes $(17 / 20$ and $20 / 23 \mathrm{~cm})$ of 'Nellie White' lilies were received from Hastings Bulb Growers (Harbor, Ore.) on 21 Oct., 2001. The mean weight of the $17 / 20 \mathrm{~cm}$ and the $20 / 23 \mathrm{~cm}$ (circumference) bulbs was 109.1 and $144.3 \mathrm{~g}$, respectively. Bulbs were case-cooled at $6{ }^{\circ} \mathrm{C}$ for 6 weeks and then treated and planted as described in Expt. 1. Plants were grown in a $18^{\circ} \mathrm{C}$ day $/ 18^{\circ} \mathrm{C}$ night glass greenhouse at a spacing of 20 plants $/ \mathrm{m}^{2}$ and were irrigated overhead from emergence to flowering two times per week with either $5^{\circ} \mathrm{C}$ (cold) or $18^{\circ} \mathrm{C}$ water using a watering can with a breaker to simulate commercial greenhouse watering practices. Volume of irrigation water applied varied from $100-150 \mathrm{~mL}$ per pot. The nutrient solution contained $375 \mathrm{mg} \cdot \mathrm{L}^{-1}$ of $\mathrm{N}$ using $15 \mathrm{~N}-0 \mathrm{P}-12.5 \mathrm{~K}$. Each bulb size was divided into two groups of 60 plants to be irrigated with each temperature solution.

For all three experiments, the following first flower opened: date of flowering, plant height from rim of pot to bottom of inflorescence, number of healthy and aborted buds and number of green and yellow leaves.

Statistical analysis. Data were subjected to analysis of variance using the Statistical Analysis System (SAS Institute, 1988). Treatment sums of squares were partitioned into linear and quadratic polynomial components using regression analysis for temperature and length of time treatments (Expt. 2). For statistical purposes, the 12-week treatment at $18^{\circ} \mathrm{C}$ was the same as the 0 -week treatment at either $2,5,8,11$, or $15^{\circ} \mathrm{C}$.

\section{Results}

Expt. 1. The effect of water temperature, method of application and time of day. With overhead irrigation, plant height showed a curvilinear response to water temperature: $\mathrm{y}_{\mathrm{o}}=0.4+4.1 \mathrm{~T}-0.10 \mathrm{~T}^{2}[\mathrm{~cm}]$, with temperature (T) in ${ }^{\circ} \mathrm{C}$ and $R^{2}=0.97$. Cold $(5$ ${ }^{\circ} \mathrm{C}$ ) water applied during the morning or afternoon produced the shortest plants (Fig. 1). The temperature of irrigation water had no basis (12 weeks). Segmented linear regresdata were collected from each plant when the

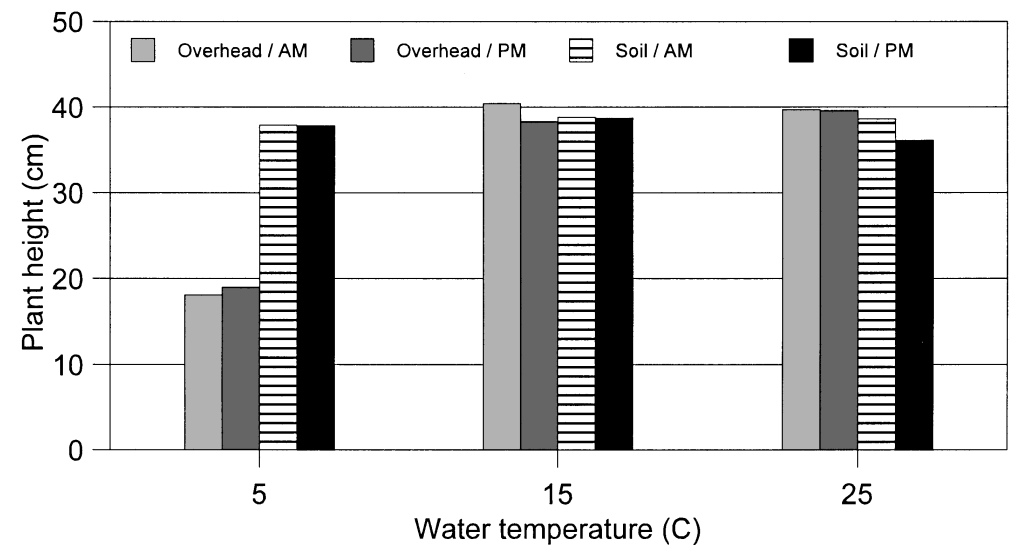

Fig. 1. Effect of irrigation water temperature $\left(5,15\right.$, or $\left.25^{\circ} \mathrm{C}\right)$ on height of 'Nellie White' Easter lilies applied either on the shoot apex (overhead) or on the substrate (soil) and either in the morning (AM) or in the afternoon (PM) (Expt. 1). Plant height was measured from rim of pot to the base of the inflorescence, when first flower opened. Each datum represents the mean of $\approx 20$ plants (standard error $=1.24$ ). effect on height: $\mathrm{y}_{\mathrm{s}}=36.9[\mathrm{~cm}]$, when applied to the substrate surface. There was a delay in flowering by $2 \mathrm{~d}$ when irrigation was applied overhead vs. substrate at $5{ }^{\circ} \mathrm{C}$. The number of healthy or aborted flower buds or number of green or yellow leaves were unaffected by water temperature, method of application or timing (data not shown).

Expt. 2. The effect of water temperature, method of application and period of application-Continuous treatment. As in Expt. 1, substrate application of nutrient solutions of different temperatures $\left(2\right.$ to $\left.18{ }^{\circ} \mathrm{C}\right)$ for the entire period between emergence and flowering (continuous) did not affect plant height of Easter lilies $\left(y_{\mathrm{s}}=49.7 \pm 2.5\right)$, but plant height increased linearly with temperature when applied to the shoot apex: $\left(\mathrm{y}_{0}=16.2+1.75 \mathrm{~T}\right.$ [cm]; $\left.r^{2}=0.88\right)$ (Fig. 2).

Limited duration of cold water treatment. Shorter plants were obtained as the total period of overhead irrigation increased (Fig. 3). From the analysis of variance (ANOVA), height response showed both a linear and quadratic response depending on the duration (weeks) of temperature treatments (Table 1). However the sums of squares of duration (week) showed that the linear portion accounted for $92 \%$ of the total variance. The same can be said for the duration $\times$ temperature interaction. Although the relationship between height and week had both a linear and quadratic form, the temperature response only differed in the linear component, but not in the quadratic component.

Water temperature and treatment duration also showed an interactive effect on the forcing time (time from planting until the day of first open flower), when the water was applied overhead. Although forcing time was not affected using the higher water temperatures $\left(11\right.$ and $15^{\circ} \mathrm{C}$ ), there was a delay in flowering as the treatment period was extended, when using cold $\left(2,5\right.$, or $\left.8^{\circ} \mathrm{C}\right)$ water (Table 2$)$. In the extreme case, the application of $2{ }^{\circ} \mathrm{C}$ water for 12 weeks overhead resulted in a 6-d delay compared to using either 11 or $15^{\circ} \mathrm{C}$ water. Water temperature and application method

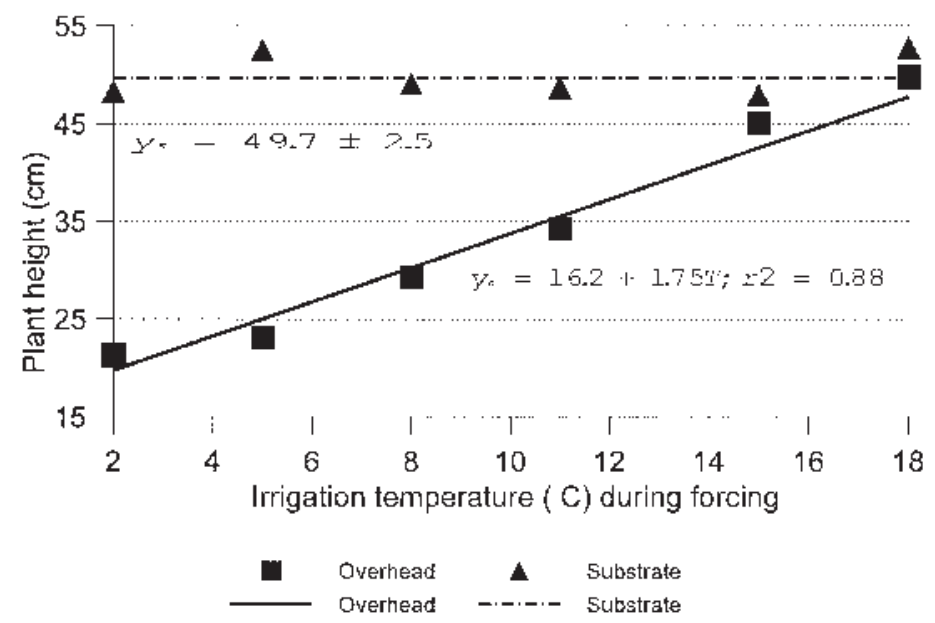

Fig. 2. Effect of irrigation water temperature $\left({ }^{\circ} \mathrm{C}\right)$ on plant height of Easter lily 'Nellie White' at flowering when applied to the substrate or the shoot apex (overhead) (Expt. 2). The treatment started at emergence and was terminated at flowering (first flower open). Plant height was measured from rim of pot to the base of the inflorescence. Each point represents the mean of 12 plants. Lines indicate values predicted by regression model. 
Table 1 . Analysis of variance of lily height to five irrigation water temperatures $(2,5,8,11$, or $15^{\circ} \mathrm{C}$ ) provided overhead for the duration of 0 to 12 weeks starting from emergence. After the temperature treatment was concluded, plants were irrigated with $18^{\circ} \mathrm{C}$ water until flowering. $R^{2}=0.89$.

\begin{tabular}{lccc}
\hline Source & df & $\begin{array}{c}\text { Mean } \\
\text { square }\end{array}$ & Pr $>$ F \\
\hline Rep & 1 & 315.9 & 0.06 \\
Temperature & 4 & 502.9 & 0.01 \\
Duration & & & \\
$\quad$ Linear & 1 & 3040 & $<0.0001$ \\
$\quad$ Quadratic & 1 & 261 & 0.002 \\
$\quad$ Lack of Fit (LoF) & 4 & 5.3 & 0.92 \\
Temp $\times$ Duration & & & \\
$\quad$ T $\times$ linear & 4 & 167.1 & 0.0002 \\
$\quad$ T $\times$ quadratic & 4 & 17.7 & 0.55 \\
$\quad$ T $\times$ LoF & 16 & 10.4 & 0.95 \\
\hline
\end{tabular}

Table 2. The effect of irrigation water temperature (overhead) and duration of treatment on the number of days to flower of Easter lily 'Nellie White'(Expt. 2). The regression was fitted to $y=$ $a+b x$, where $y=$ number of days to first flower 'open' since the day of potting case-cooled lily bulbs and $\mathrm{x}=$ number of weeks of irrigation treatment at a given temperature $\left({ }^{\circ} \mathrm{C}\right)$ since emergence. s.e. $_{\mathrm{a}}=0.6$; s.e. $_{\mathrm{b}}=0.13 ; R^{2}=0.66$.

\begin{tabular}{ll}
\hline $\begin{array}{l}\text { Irrigation } \\
\text { temperature }\left({ }^{\circ} \mathrm{C}\right)\end{array}$ & $\begin{array}{c}\text { Regression for } \\
\text { days to flower }\end{array}$ \\
\hline 15 & $\mathrm{y}_{15}=111.7$ \\
11 & $\mathrm{y}_{11}=111.7$ \\
8 & $\mathrm{y}_{8}=111.7+0.30 \mathrm{x}$ \\
5 & $\mathrm{y}_{5}=111.7+0.37 \mathrm{x}$ \\
2 & $\mathrm{y}_{2}=111.7+0.52 \mathrm{x}$ \\
\hline
\end{tabular}

had no effect on the total number of healthy buds $(5.5 \pm 0.2)$ or number of aborted buds (0.05) per plant.

Weekly growth measurements. Weekly measurements allowed us to calculate the height difference between plants given a cold temperature $\left(2,5,8\right.$, or $\left.11^{\circ} \mathrm{C}\right)$ for a specific period $(2,4,6$, or 8 weeks) followed by 18 ${ }^{\circ} \mathrm{C}$ for the remainder of the time and the height of those plants given the same temperature on a continuous basis (12 weeks). The junction point (j) provides an estimate of how long the response to a cold water treatment remained in effect after the treatment was terminated (Fig. 4). The junction point for the 2-week period $\left(\mathrm{P}_{2}\right)$ was $\approx 3.4$ weeks, which meant that the plants maintained a similar rate of elongation for another $10 \mathrm{~d}$ (1.4 weeks) after the treatment stopped. This intercept was similar for both 2,5 , and $8{ }^{\circ} \mathrm{C}$ water treatments when given for 2 weeks, while ProcNLIN failed to converge for $11^{\circ} \mathrm{C}$. For $\mathrm{P}_{4}$, the intercept was 5.8 weeks or $13 \mathrm{~d}$ (1.8 weeks) after the cold water treatment stopped. The intercept for $\mathrm{P}_{6}$ was $\approx 6$ weeks, implying that there is hardly any residual effect after the 6 weeks of treatment. It is unclear at this point whether this difference in response is plant related, a seasonal effect (involving increasing air temperature and light) or purely mechanical as the shoot apex at this stage (visible bud stage) is more open, allowing the water to run more quickly through the apex, and therefore having less time to influence the temperature of the shoot

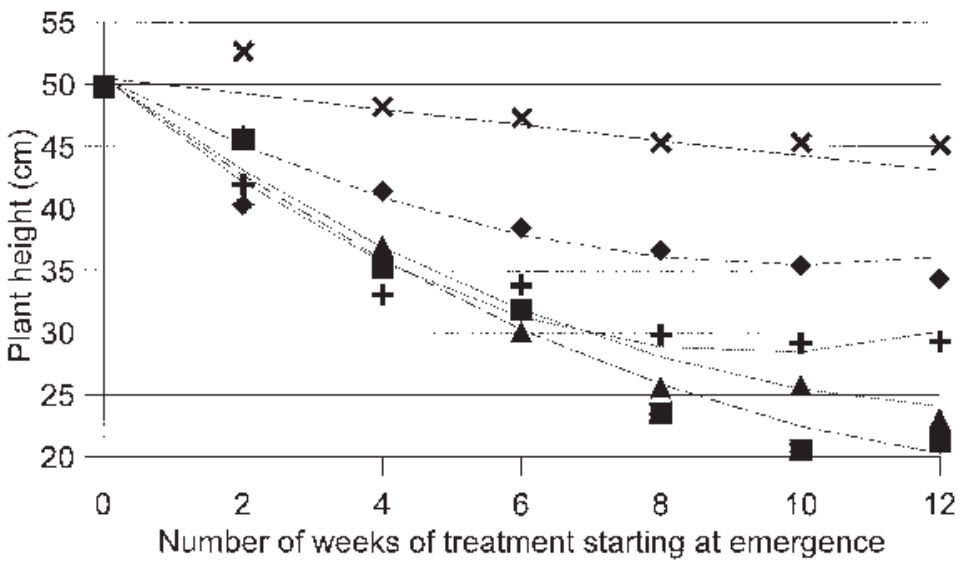

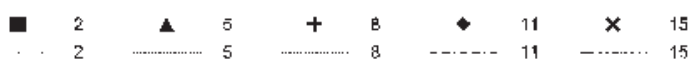

Fig. 3. Effect of irrigation water temperature $\left({ }^{\circ} \mathrm{C}\right)$ on plant height of Easter lily 'Nellie White' when applied overhead (to the shoot apex) (Expt. 2).The treatments started at emergence with increasing intervals of 2 weeks. After the treatment period with a given water temperature ended, the plants were irrigated with $18^{\circ} \mathrm{C}$ water until flowering. Plant height $(\mathrm{H})$ was determined from rim of pot to the base of the inflorescence at flowering. Each data point represents the mean of 12 plants; regression analysis (drawn lines) provided the following equations: $\mathrm{H}_{15}=50.5-0.62 \mathrm{x} ; \mathrm{H}_{11}=50.5-3.0 \mathrm{x}+0.15 \mathrm{x}^{2} ; \mathrm{H}_{8}=50.5-4.7 \mathrm{x}$ $+0.25 \mathrm{x}^{2} ; \mathrm{H}_{5}=50.5-4.0 \mathrm{x}+0.15 \mathrm{x}^{2} ; \mathrm{H}_{2}=50.5-4.2 \mathrm{x}+0.14 \mathrm{x}^{2}$; where $\mathrm{x}$ is the number of weeks of the irrigation water treatment; $R^{2}=0.82$.
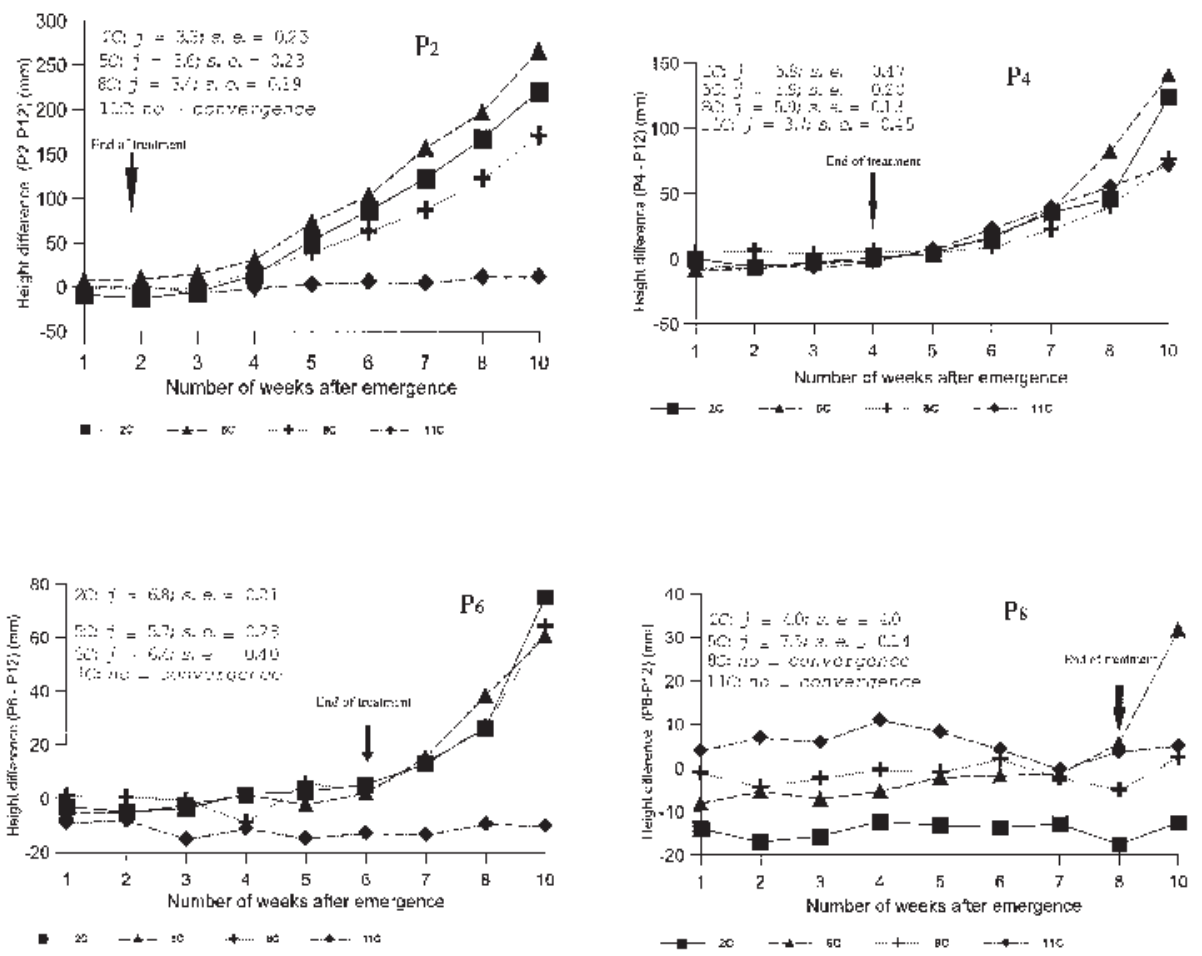

Fig. 4. Differences in plant height of Nellie White Easter lilies, which were watered overhead with different irrigation water temperatures $\left(2,5,8\right.$, or $\left.11^{\circ} \mathrm{C}\right)$ for $2,4,6$, or 8 weeks $(\mathrm{P} 2$ - P8) beginning at emergence followed by irrigation temperature of $18{ }^{\circ} \mathrm{C}$ and those treated continuously with the respective water temperature (Expt. 2). The estimated junction point (j) is the week number that the plant height of those plants treated overhead with a particular water temperature started to deviate from those treated continuously with a particular temperature.

apex. Data for $\mathrm{P}_{8}$ was suspect due to the fact that at this time visible bud stage was reached and the point of reference for height measurement changed.

A typical response of the different water temperatures showed that the shoot tip reached a minimum after $\approx 4$ min after pouring the water on the meristem (Fig. 5), while it took more than $1 \mathrm{~h}$ to return to the initial temperature. The minimum shoot temperatures were $8,10,12.5$, 14 , and $15.5^{\circ} \mathrm{C}$ for water temperatures of 2 , $5,8,11$, and $15^{\circ} \mathrm{C}$, respectively.

Expt. 3. Role of bulb size in response to water temperature. Cold $\left(5^{\circ} \mathrm{C}\right)$ water applied overhead produced plants that were $59 \%$ and $52 \%$ shorter than the plants receiving $18^{\circ} \mathrm{C}$ water for the $17 / 20$ and $20 / 23$ bulb sizes, respectively (data not shown). The larger bulbs 

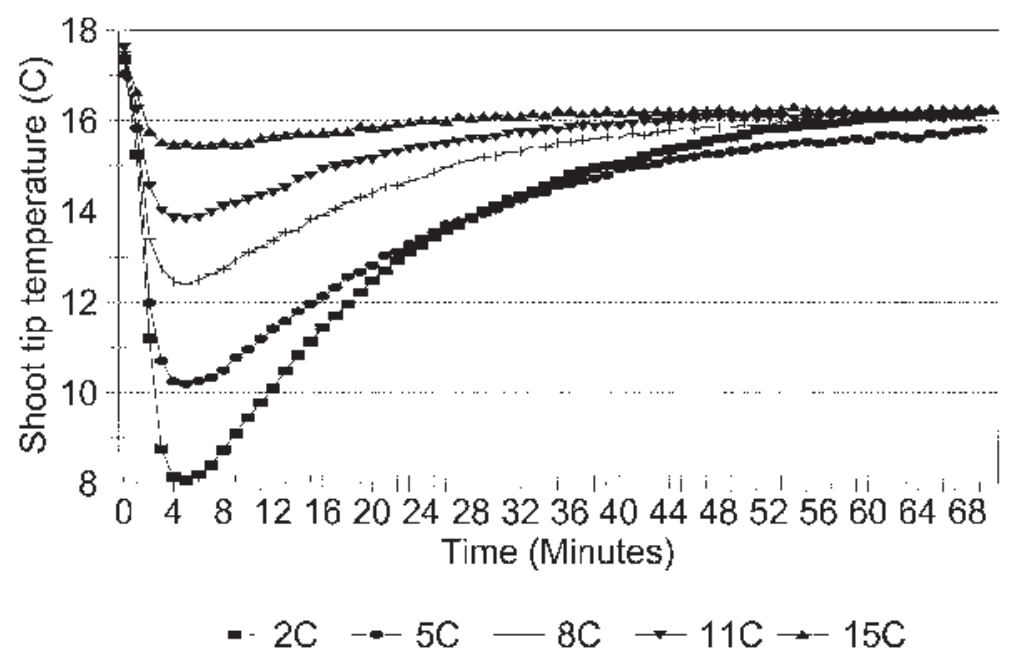

Fig. 5. Effect of pouring $100 \mathrm{~mL}$ of $2,5,8,11$, or $15^{\circ} \mathrm{C}$ water on the shoot tip of Easter lily 'Nellie White' grown in a $18{ }^{\circ} \mathrm{C}$ greenhouse (Expt. 2). Shoot tip measurements were taken on a cloudy day (17 Feb. 2003) with greenhouse air temperature of $18.3^{\circ} \mathrm{C}$ by inserting a thermocouple in the growing shoot prior to applying the water. Data represent the mean of two plants.

produced slightly taller plants than the smaller bulbs due to the higher leaf number (data not shown) and increased number of flower buds (7.0) than the smaller bulbs (5.2). Cold water overhead-treated plants required an additional $3 \mathrm{~d}$ to mature (data not shown).

\section{Discussion}

Decreasing irrigation water temperature reduced plant height of Easter lilies when the nutrient solution was applied to the shoot apex, but not when applied to the growing medium (Figs. 1 and 2). Height reduction of $50 \%$ to $60 \%$ was achieved with 2 or $5^{\circ} \mathrm{C}$ water applied between emergence and flowering (compared to $18^{\circ} \mathrm{C}$ ) and is considerably more than that normally achieved when the day/night temperature differential is negative (Erwins and Heins, 1995) or when twilight is removed (Blom et al., 1995). This effect of cold water appeared to be independent of the time-of-day of application (Expt. 1), and therefore unlikely related to the same mechanism as that for the day/night temperature differential. The effect of the cold water was quite dramatic considering that the temperature of the shoot apex was affected for $<1 \mathrm{~h}$ (Fig. 5) after each overhead irrigation made every $3-4 \mathrm{~d}(\approx 100 \mathrm{~h})$, which is $1 \%$ of the time. This treatment affected both height and rate of development (flowering date). There was a negative correlation between the number of days to flower and plant height (Pearson correlation coefficient $=-0.38 ; P<0.0001)$. It appeared that the inhibitory effect on elongation was stronger at the beginning of the treatment period compared to later (visible bud stage to flowering). It is unclear whether this treatment effect was related to the stage of plant development or simply that the retention time of the water in the shoot apex was shorter after the Easter lily reached visible bud stage, at which time the growing point became more open. These experiments did not estimate the minimum water volume needed to obtain the "cold shock" response, how quickly to apply the water, or both. In Expts. 1 and 2, the water was poured from a beaker on the top of the shoot, while in Expt. 3 we applied the water more slowly with a breaker (similar to commercial practice) but using the same volume. The same effect may be obtained with a smaller volume of water, but given in a split application. The "cold shock" must induce a prolonged change in the physiological status of the shoot apex. In this study, the response of Easter lilies showed a carryover-effect of $\approx 10$ $\mathrm{d}$ after treatment with cold water was stopped temperatures above that of air temperature did not affect plant height, as plants irrigated with $15^{\circ} \mathrm{C}$ had the same height as those with $25^{\circ} \mathrm{C}$ (Expt. 1).

The physiological basis for this "cold shock" phenomenon remains unclear. However application of cold water to the shoot apex has proven to be an effective, nonchemical height control treatment that has no effect on number of buds, aborted buds or leaf yellowing. However, flowering was delayed by a number of days, especially when lower temperatures $\left(2\right.$ and $5{ }^{\circ} \mathrm{C}$ ) were applied for longer periods of time. The application of cold water commercially may be relatively easy when using pond water during winter in high latitude areas. However, when using and replaced with $18{ }^{\circ} \mathrm{C}$ water (Fig. 4). Water cistern or well water or during summer, a water chiller may be an option. This technique is another nonchemical tool in making decisions during "graphical tracking." Other crops, such as bedding plants, are being trialed.

\section{Literature Cited}

Blom, T.J., M.J. Tsujita, and G.L. Roberts. 1995. Farred at end of day and reduced irradiance affect plant height of Easter and Asiatic hybrid lilies. HortScience. 30:1009-1012.

Chen, J.J., Y.W. Sun, and T.F. Sheen. 1999. Use of cold water for irrigation reduces stem elongation of plug-grown tomato and cabbage seedlings. HortScience. 34:852-854.

Erwin, J.E. and R.D. Heins. 1990. Temperature effects on lily development rate and morphology from the visible bud stage until anthesis. J. Amer. Soc. Hort. Sci. 115:644-646.

Erwin, J.E. and R.D. Heins. 1995. Thermomorphogenic responses in stem and leaf development. HortScience. 30:940-949.

Erwin, J.E., R.D. Heins, M.G. Karlsson, R. Berghage, W. Carlson, and J. Biernbaum. 1987. The basics on Easter lilies: Light and temperature. GrowerTalks 51(7):84-86, 88, 90.

Fisher, P.R., R.D. Heins, N. Ehler, and J.H. Lieth. 1997. A decision-support system for real-time management of Easter lily (Lilium longiflorum Thunb.) scheduling and height. I. System description. Agr. Systems 54(1):23-38.

Heins, R.D., H.B. Pemberton, and H.F. Wilkins. 1982. The influence of light on lily (Lilium longiflorum Thunb.). I. Influence of light intensity on plant development. J. Amer. Soc. Hort. Sci. 107:330-335.

Jiao,J., M.J. Tsujita, and D.P. Murr. 1986. Effects of paclobutrazol and A-Rest on growth, flowering, leaf carbohydrate and leaf senescence in 'Nellie White' Easter lily (Lilium longiflorum Thunb.). Scientia Hort. 30:135-141.

Larson, R.A., H.K. Tayama, and T.J. Roll. 1990. Tips on growing potted Easter lilies. Ohio Coop. Ext. Serv. Bul. FP-768. Agdex 281/15.

Mitchell, C.A. 1996. Recent advances in plant response to mechanical stress: Theory and application. HortScience 31:31-35.

Moe, R. and R.D. Heins. 1990. Control of plant morphogenesis and flowering by light quality and temperature. Acta Hort. 272:81-89.

Mortensen, L.M. and E. Stromme. 1987. Effects of light quality on some greenhouse crops. Scientia Hort. 33:27-36.

Rajapakse, N.C., R.E. Young, M.J.McMahon, and Ryu Oi. 1999. Plant height control by photoselective filters: Current status and future prospects. HortTechnology 9:618-624

SAS Institute. 1988. SAS/STAT user's guide. version 8. SAS Inst., Cary, N.C.

Smith, D.R. and R.W. Langhans. 1962. The influence of photoperiod on the growth and flowering of Easter lily (Lilium longiflorum Thunb. var. Croft). Proc. Amer. Soc. Hort. Sci. 80:599-604.

Wilkins, H.F., W.E. Waters, and R.E. Widmer. 1968. Influence of temperature and photoperiod on growth and flowering of Easter lilies (Lilium longiflorum Thunb. 'Georgia', 'Ace' and 'Nellie White'). Proc. Amer. Soc. Hort. Sci. 93: 640-649. 